\title{
TOUGHENING OF COMPLETE SOLID SOLUTION CERMETS BY GRAPHITE ADDITION
}

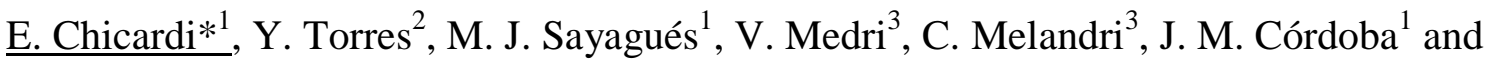
F. J. Gotor ${ }^{1}$.

${ }^{1}$ Instituto de Ciencia de Materiales de Sevilla (US-CSIC), Av. Américo Vespucio, 49, 41092 Sevilla, Spain.

${ }^{2}$ Departamento de Ingeniería Mecánica y de los Materiales, E.T.S. de Ingeniería, Universidad de Sevilla, Avda. Camino de los Descubrimientos, s/n, 41092 Sevilla, Spain.

${ }^{3}$ Institute of Science and Technology for Ceramics (CNR-ISTEC), Via Granarolo 64, 48018 Faenza, Italy.

\begin{abstract}
$\left(\mathrm{Ti}_{0.95} \mathrm{Ta}_{0.05}\right)\left(\mathrm{C}_{0.5} \mathrm{~N}_{0.5}\right)$-Co complete solid solution cermets (CSCs) were developed by a mechanochemical synthesis process and a pressureless sintering method. The effect of different percentages of graphite used as a sintering additive on the nature of the binder phase and the mechanical properties of the cermets was investigated. Microstructural and mechanical characterisations were carried out by X-ray diffraction, optical microscopy, scanning electron microscopy, transmission electron microscopy, energydispersive X-ray spectroscopy, Vickers hardness, indentation fracture toughness and nanoindentation. The addition of graphite modified the carbon activity during sintering, reducing the dissolution of carbonitride ceramic particles into the molten binder. The amount of $\mathrm{Ti}$ and $\mathrm{Ta}$ remaining in the binder after sintering gradually decreased as the amount of graphite added increased, which induced a change in the nature of the binder phase. When no graphite was added, the binder consisted of the brittle $\mathrm{Ti}_{\mathrm{x}} \mathrm{Ta}_{1-\mathrm{x}} \mathrm{Co}_{2}$
\end{abstract}


intermetallic phase. With the increase in the amount of graphite added, the formation of more ductile phases, such as $\mathrm{Ti}_{\mathrm{x}} \mathrm{Ta}_{1-\mathrm{x}} \mathrm{Co}_{3}$ and $\alpha$-Co, was observed, causing a significant improvement in the toughness of the cermets.

Keywords: Titanium carbonitride; Cermet; Toughness; Nanoindentation; Graphite; Intermetallics.

*Corresponding Author. Tel: +34 954489217. E-mail: ernesto.chicardi@icmse.csic.es

\section{Introduction.}

Cermets are ceramic-metal composites currently used in the production of tungsten-free cemented carbides for cutting tools [1]. Typically, cermets consist of titanium carbide $(\mathrm{TiC})$ or titanium carbonitride $(\mathrm{Ti}(\mathrm{C}, \mathrm{N}))$ ceramic particles embedded in a $\mathrm{Co} / \mathrm{Ni}$ metal alloy that acts as a binder [2-5]. Cermets combine the advantages of ceramics and metals [3]; the ceramic phase must mainly provide hardness and wear resistance, whereas the binder phase provides fracture strength and impact resistance [6]. For the hard component, other binary carbides, such as $\mathrm{TaC}, \mathrm{NbC}, \mathrm{Mo}_{2} \mathrm{C}, \mathrm{WC}$, $\mathrm{HfC}, \mathrm{VC}$ and $\mathrm{ZrC}$, are added to improve specific properties, for example, thermal shock resistance, hot hardness, chemical stability at high temperature, oxidation resistance and high-temperature creep resistance [7-11]. The binder phase can also contain other minor metallic components ( $\mathrm{Al}, \mathrm{Cr}, \mathrm{Mo}, \mathrm{Fe}, \mathrm{Mn}, \mathrm{V}$ or $\mathrm{Ce}$ ) to support microstructure refinement, particulate dispersion, hardening of the binder and improvement of corrosion resistance $[12,13]$.

Some of those good chemical, physics and mechanical properties makes cermets positively compared with conventional bulk and coated hard metals (WC-Co). They possess a superior cutting performance such as high cutting speeds at moderate chip 
cross-sections, performance reliability, surface quality of the machined piece, etc [7]. Particularly, the typical applications for cermets based on titanium carbonitride include high performance cutting and forming tools, high-speed milling, semi-finishing and finishing works of carbon steel and stainless steel, high-corrosion resistance coatings for molten metal containers, thermal barriers in fusion and chemical reactors and diffusion barriers in semiconductor technologies $[14,15]$.

For fabricating cermets, the different starting materials are generally mixed by wet milling, and the resulting powder mixture, after being dried, is compacted and sintered in an inert atmosphere $\left(\mathrm{Ar}, \mathrm{He}, \mathrm{N}_{2}\right)$ or in vacuum at a temperature of $1400-1500{ }^{\circ} \mathrm{C}$ for a period of 1 to $3 \mathrm{~h}[1,16,17]$. It is well known that during liquid-phase sintering ceramic particles in cermets develop a characteristic core-rim microstructure via a dissolutionreprecipitation process. The core corresponds to the undissolved original $\operatorname{Ti}(\mathrm{C}, \mathrm{N})$ particles, and the rim is a newly formed carbonitride solid solution phase, (Ti, Mt1, $\mathrm{Mt} 2, \ldots)(\mathrm{C}, \mathrm{N})$, which contains $\mathrm{Ti}$ and the other transition metals added as binary carbides [18]. The core-rim microstructure has a strong influence on the mechanical properties of cermets, and it is believed that the rim phase is the most responsible for the good mechanical behaviour of the final material. For this reason, the use of these carbonitride solid solution phases as raw ceramic materials in the manufacture of cermets has been proposed [19]. Furthermore, the development of so-called complete solid solution cermets (CSCs), in which the ceramic particles are composed only of a homogeneous solid solution single phase (without the core-rim microstructure), has been anticipated as the only way to approach the toughness values characteristic of hard metals because the strain developed at the interface between the core and rim phases, which facilitates crack propagation during machining, can be avoided [20]. 
In a recent study [21], CSCs based on $(\mathrm{Ti}, \mathrm{Ta})(\mathrm{C}, \mathrm{N})$ single phase were developed by exploiting the ability of the mechanochemical process referred to as mechanically induced self-sustaining reaction (MSR) [22] to yield homogeneous carbonitride solid solution powders [23-25]. This method uses the strong exothermic character of carbonitride formation from the starting materials to promote self-propagating reactions by the mechanical energy supplied by high-energy ball mills.

Planetary mills are the typical devices used at laboratory scale to carry out these combustion reactions $[23,26]$. However, there are now some industrial planetary mills $[27,28]$, with a really high capacity, where it would be possible to implement those reactions by a simply and efficiently way at industrial scale.

After sintering, the resulting binder in these CSCs was observed to be a $\operatorname{Ti}_{\mathrm{x}} \mathrm{Ta}_{1-}$ ${ }_{\mathrm{x}} \mathrm{Co}_{2}$ intermetallic phase instead of the initial elemental Co. The presence of intermetallics in cermets, which precipitate during cooling, is not a new phenomenon [2, $29,30]$ and has been associated with the excessive dissolution of the ceramic particles in the molten binder, causing Ti enrichment. Although some authors have shown that ductile intermetallic alloys, especially aluminides, are good candidates for binders because the mechanical properties of cermets can be retained at high temperature [ 31 , 32], the formation of brittle intermetallics during sintering, such as $\mathrm{Ti}_{\mathrm{x}} \mathrm{Ta}_{1-\mathrm{x}} \mathrm{Co}_{2}$, can be extremely harmful for cermets, greatly damaging the fracture strength and toughness [8].

The effect of carbon activity on the coarsening of WC grains during liquid phase sintering has been extensively studied in hard metals [33, 34]. Moreover, it has been observed in $\operatorname{Ti}(\mathrm{C}, \mathrm{N})$-based cermets that the grain growth rate of ceramic particles depends on the particles' solubility in the binder, which in turn depends on the $\mathrm{C} / \mathrm{N}$ 
ratio, decreasing with a decrease in carbon content [35]. In this respect, it has been reported that the use of carbon as an additive can modify the microstructure and mechanical properties of cermets, as the dissolution of ceramic particles is affected [36, 37]. Some authors have indicated that the presence of intermetallic phases observed in cermets is the consequence of the considerable dissolution of $\mathrm{Ti}$ in the molten binder promoted by denitridation processes, especially when sintering is performed under low nitrogen partial pressure [38].

In this context, the aim of this study was to develop (Ti,Ta)(C,N)-Co CSCs with high fracture toughness using the MSR mechanochemical process and carbon as a sintering additive. This goal was achieved, preventing the formation of brittle intermetallics via the reduction of the driving force (carbon activity) of ceramic dissolution during liquid phase sintering. In this study, different amounts of graphite were added to a cermet powder mixture, and after sintering, the chemical composition, microstructure and mechanical properties were characterised to relate the nature of the binder to the mechanical behaviour of the cermets.

\section{Experimental.}

\subsection{Development of cermets.}

Ti (99\% purity, < 325 mesh, Strem Chemicals), Ta (99.6\% purity, < 325 mesh, Alfa-Aesar), graphite ( $<270$ mesh, Fe $\leq 0.4 \%$, Merck) and Co powders (99.8\% purity, $<100$ mesh, Strem Chemicals), together with $\mathrm{N}_{2}\left(\mathrm{H}_{2} \mathrm{O}\right.$ and $\mathrm{O}_{2} \leq 3 \mathrm{ppm}$, Air Liquide), were used as raw materials to develop the $(\mathrm{Ti}, \mathrm{Ta})(\mathrm{C}, \mathrm{N})-\mathrm{Co} \mathrm{CSCs}$. First, the ceramic phase, i.e., the Ti-Ta carbonitride solid solution with nominal composition $\mathrm{Ti}_{0.95} \mathrm{Ta}_{0.05} \mathrm{C}_{0.5} \mathrm{~N}_{0.5}$, was synthesised from the starting materials by the mechanochemical MSR process using a planetary mill (Pulverisette 4, Fritsch) that allowed for operation 
at a constant gas pressure and for the detection of self-propagating reactions during milling [39]. This composition was chosen according to a previous study that showed that the presence of Ta significantly improves the oxidation resistance of cermets [40], which is of crucial importance for high-temperature applications.

Concretely, $46.5 \mathrm{~g}$ of an elemental $\mathrm{Ti}$, Ta, and graphite powder mixture with an atomic Ti:Ta:C ratio of 0.95:0.05:0.5 were placed together with thirteen tempered steel balls $(\mathrm{d}=20 \mathrm{~mm}, \mathrm{~m}=32.6 \mathrm{~g})$ in a $300 \mathrm{ml}$ tempered steel vial $(67 \mathrm{Rc})$ and ball milled under 6 atm of $\mathrm{N}_{2}$ at a spinning rate of $400 \mathrm{rpm}$, for both the rotation of the supporting disc and the superimposed rotation in the direction opposite to the vial. After detecting ignition, milling was prolonged for 5 min to ensure full conversion [21].

Subsequently, the carbonitride solid solution phase was mixed by dry milling (Pulverisette 7 planetary mill, Fritsch) with 20 wt.\% or 30 wt.\% of Co and different small amounts of $\mathrm{C}$ in the form of graphite from $0 \mathrm{wt} . \%$ to $2.2 \mathrm{wt} \%$ to obtain the powdered cermets. They were introduced together with seven tempered steel balls $(d=$ $15 \mathrm{~mm}, \mathrm{~m}=13.7 \mathrm{~g})$ in a $45 \mathrm{ml}$ tempered steel vial $(67 \mathrm{Rc})$ and ball milled under $6 \mathrm{~atm}$ of high-purity helium gas $\left(\mathrm{H}_{2} \mathrm{O}<3 \mathrm{ppm}, \mathrm{O}_{2}<2\right.$ ppm and $\mathrm{CnH}_{\mathrm{n}}<0.5 \mathrm{ppm}$, Air Liquide) at a spinning rate of $600 \mathrm{rpm}$. The mixture was milled for $30 \mathrm{~min}$, which was the minimum time necessary to produce the optimal homogenisation of the powdered cermets, as required to achieve an optimal densification after sintering [21] .

The nominal compositions of the different cermets studied in this work are presented in table 1 . Cermets were labelled as $x$ CoyG, where $x$ and $y$ are the nominal weight percentages of Co and graphite, respectively.

The powdered cermets were shaped in a uniaxial press ( 2 tons- 5 min) using a stainless steel die and compacted by cold isostatic pressing (200 MPa-10 min). The 
green bodies were sintered at $1500^{\circ} \mathrm{C}$ for 60 min (heating and cooling rate $=5^{\circ} \mathrm{C} / \mathrm{min}$ ) under argon flow $\left(\mathrm{H}_{2} \mathrm{O} \leq 8 \mathrm{ppm}\right.$ and $\mathrm{O}_{2} \leq 2 \mathrm{ppm}$, Linde) in a horizontal tubular furnace (IGM1360 model no. RTH-180-50-1H, AGNI), yielding cylindrical cermets measuring $13 \mathrm{~mm}$ in diameter and $9 \mathrm{~mm}$ in height.

\subsection{Chemical, microstructural and physical characterisation.}

The bulk density of the samples was measured using Archimedes' method with distilled water impregnation (ASTM C373-88) due to the procedure's experimental simplicity and reliability. Measurements were performed on five representative test specimens for each cermet.

X-ray diffraction (XRD) patterns of cross-sectional polished surfaces were obtained with a PANalytical X'Pert Pro instrument equipped with a $\theta / \theta$ goniometer, using $\mathrm{Cu} \mathrm{K \alpha}$ radiation $\left(40 \mathrm{kV}, 40 \mathrm{~mA}\right.$ ), a secondary $\mathrm{K}_{\beta}$ filter and an $\mathrm{X}^{\prime}$ Celerator detector. The diffraction patterns were scanned from $20^{\circ}$ to $140^{\circ}(2 \theta)$ in step-scan mode with a step size of $0.02^{\circ}$ and a counting time of $275 \mathrm{~s} / \mathrm{step}$. Silicon powder (Standard Reference Material 640c, NIST) was used for calibration of the diffraction line positions. The space group symmetry as well as the lattice parameters of the ceramic and binder phases were calculated from the complete set of peaks in the XRD diagrams using the Fullprof Suite software program, which features the Dicvol, WinPLOTR and FullProf software programs. The elucidated structures were compared with those in the PDF-4+ database from the International Centre for Diffraction Data (ICDD).

Scanning electron microscopy (SEM) images of cross-sectional polished surfaces were obtained on a Hitachi S-4800 field emission SEM in secondary electron mode at an acceleration voltage of $5 \mathrm{kV}$. The $\mathrm{Ti}$, Ta and Co contents in both the ceramic and binder phases were measured by X-ray energy dispersive spectrometry (XEDS) with a 
detector coupled in the SEM using an acceleration voltage of $20 \mathrm{kV}$. For each phase in the cermets, 10-20 measurements were performed. SEM images at different magnifications ( $1 \mathrm{kX}, 2 \mathrm{kX}$ and $5 \mathrm{kX}$ ) were employed to evaluate, by Image Analysis (IA) using the Image-Pro Plus 6.2 software program, the average ceramic particle size (d), the volume percentage of the binder phase $(\mathrm{BF})$ and the volume percentage of porosity (p).

Transmission electron microscopy (TEM) images and selected area electron diffraction (SAED) patterns were obtained on a 200-kV Philips CM200 TEM equipped with a SuperTwin objective lens and a LaB6 filament (point resolution $=0.25 \mathrm{~nm}$ ). Thin discs of cermets with $\varnothing=3 \mathrm{~mm}$ were prepared by cutting, polishing, dimpling and ion milling, successively. JEMS software was used to resolve the structures obtained by SAED. Semi-quantitative XEDS-TEM analyses were carried out using a Gatan detector coupled to the TEM.

\subsection{Mechanical behaviour.}

Hardness measurements were carried out on polished surfaces at an indentation load of $5 \mathrm{kgf}\left(\mathrm{HV}_{5}\right)$ using a Vickers diamond pyramidal indenter (Zwick 3212). No artefacts from the indentation load effect were observed at $5 \mathrm{kgf}$. The indentation time was $15 \mathrm{~s}$. Ten indentations were made for each cermet.

The fracture toughness, $\mathrm{K}_{\mathrm{IC}}$, was evaluated by the indentation microfracture (IM) method using the crack length produced at the corners of Vickers indentations and the equation from Niihara [41]:

$$
K_{I C}=0.0889 \cdot(H V)^{1 / 2} \cdot(P \cdot 4 l)^{1 / 2},
$$

where $P$ denotes the load, $l$ the crack length and $H V$ the estimated hardness. 
This method has proved to give reasonable estimates of $\mathrm{K}_{\mathrm{IC}}$ in cemented carbides up to values of approximately $15 \mathrm{MPam}^{1 / 2}$ with maximum deviations of $20 \%$ compared with fracture toughness data obtained from single-edge-notched-beam specimens [42]. A load of $50 \mathrm{kgf}$ was used to produce cracks with at least half the length of the indentation diagonal, which is the minimum length required to obtain $\mathrm{K}_{\mathrm{IC}}$ values independent of the load [43]. Accurate measurements of crack lengths were made using optical (Epiphot 200, Nikon) and scanning electron microscopy.

Nanoindentation tests were conducted to determine the hardness $(\mathrm{H})$ and Young's modulus $(\mathrm{E})$ of the ceramic and binder phases and were performed on polished surfaces using a commercial nanoindenter (Nano Indenter XPTM, MTS Systems Corporation, Oak Ridge, TN, USA) fitted with a Berkovich diamond tip. The response from individual phases was measured using the grid method, in which 200 indentations were made with maximum load of $5 \mathrm{mN}$. The indenter was continuously loaded up to the peak load in $15 \mathrm{~s}$ and immediately unloaded without a holding time. Both $\mathrm{H}$ and $\mathrm{E}$ were calculated using the data acquisition software equipped with the nanoindenter, which is based on Oliver and Pharr's model [44]. A Poisson ratio of 0.3 was used to calculate E. The raw load-displacement data were automatically corrected for the machine compliance and thermal drift by the software. The area function of the indenter tip was calibrated using a standard fused silica specimen before testing.

\section{Results and discussions.}

\subsection{Synthesis and sintering of CSCs.}

$\mathrm{A} \mathrm{Ti}, \mathrm{Ta}$ and $\mathrm{C}$ powder mixture with an atomic ratio of $0.95 / 0.05 / 0.5$, corresponding to a nominal composition of $\mathrm{Ti}_{0.95} \mathrm{Ta}_{0.05} \mathrm{C}_{0.5} \mathrm{~N}_{0.5}$, was ball-milled under a $\mathrm{N}_{2}$ atmosphere in a Pulverisette 4 planetary mill. After 35 min of milling (ignition time), 
the occurrence of a self-sustaining reaction inside the vial (MSR process) was detected and associated with the formation of the carbonitride ceramic phase, as observed in previous works $[21,45]$. The milling was prolonged for $5 \mathrm{~min}$ after ignition to ensure the completion of the reaction. The XRD pattern of the obtained powder (figure 1a) confirmed the formation of a single phase with a cubic structure and Fm-3m space group symmetry. The $2 \theta$ position of the reflections, which lay between those of the Ta and Ti carbides and nitrides (reference patterns TiN (38-1420), TiC (32-1383), TaC (350801) and $\mathrm{TaN}$ (49-1283)), indicated the formation of a Ti-Ta carbonitride solid solution.

The carbonitride phase was then mixed by dry milling in the Pulverisette 7 planetary mill for $30 \mathrm{~min}$ with Co and graphite in different proportions to obtain the set of powdered cermets listed in table 1 . The XRD patterns of different powdered cermets were identical, showing only the presence of the carbonitride and Co phases. As representative samples, the powdered cermets $20 \mathrm{Co} 1.8 \mathrm{G}$ and $30 \mathrm{Co} 1.8 \mathrm{G}$ are shown in figures $1 \mathrm{~b}$ and $1 \mathrm{c}$. The absence of reflections corresponding to graphite in the XRD patterns is due to the small amount of graphite added and the high capacity of highenergy milling for introducing defects and disorder into the lamellar structure of graphite [46]. Concerning the ceramic phase, less intense and broad reflections were observed as a direct consequence of the second milling treatment that induced a refined microstructure and the creation of defects. No chemical or crystallographic modification was observed.

The XRD patterns of the cermets after sintering (figure 2) again revealed the reflections corresponding to the carbonitride phase, which remained practically at the same $2 \theta$ positions as those of the powdered cermets independently of the amount of added graphite, suggesting no significant compositional modifications. The most 
significant effect induced by the addition of graphite was observed for the reflections associated with the binder phase. The changes shown in figure 2 for both the 20 CoyG and 30CoyG series clearly indicate variations in the characteristics of the binder as the amount of graphite was increased. The structure and stoichiometry of different phases acting as a binder were elucidated using DICVOL software, Ti-Co, Ta-Co and Ti-Ta-Co phase diagrams $[47,48]$ and PDF-4+ files from the ICDD.

For the $20 \mathrm{CoyG}$ series (figure $2 \mathrm{a}$ ), the presence of the $\mathrm{Ti}_{\mathrm{x}} \mathrm{Ta}_{1-\mathrm{x}} \mathrm{Co}_{2}$ intermetallic compound with cubic structure and Fd-3m space group symmetry was observed for the cermet to which no graphite was added (20Co0G). The position of the (311) reflection for this compound at $2 \theta=44.80^{\circ}$ between the positions of the reflection for $\operatorname{TiCo}_{2}(2 \theta=$ $\left.45.02^{\circ}\right)$ and $\mathrm{TaCo}_{2}\left(2 \theta=44.48^{\circ}\right)$ agrees with the solubility of $\mathrm{Ta}$ in the $\mathrm{TiCo}_{2}$ structure and the formation of an intermetallic solid solution. Moreover, the presence of $\mathrm{Ti}$ and Ta in the binder phase was determined by XEDS-SEM and XEDS-TEM, as will be discussed later. When a small amount of graphite was added, 0.5 wt.\% (20Co0.5G), no differences were observed in the binder phase, and the same $\mathrm{Ti}_{\mathrm{x}} \mathrm{Ta}_{1-\mathrm{x}} \mathrm{Co}_{2}$ intermetallic compound was observed.

However, after the addition of 1 wt.\% of graphite (20Co1G), two different binder phases were detected. Again, a $\mathrm{Ti}_{\mathrm{x}} \mathrm{Ta}_{1-\mathrm{x}} \mathrm{Co}_{2}$ intermetallic compound with 1:2 stoichiometry, but in this case with hexagonal structure and $\mathrm{P} 63 / \mathrm{mmc}$ space group symmetry, and a $\mathrm{Ti}_{\mathrm{x}} \mathrm{Ta}_{1-\mathrm{x}} \mathrm{Co}_{3}$ compound (1:3 stoichiometry) with cubic structure and Pm-3m space group symmetry were observed. When a greater amount of graphite was added (20Co1.4G), the binder evolved in such a way that the content of the $\mathrm{Ti}_{\mathrm{x}} \mathrm{Ta}_{1-\mathrm{x}} \mathrm{Co}_{3}$ phase increased at the expense of that of the $\mathrm{Ti}_{\mathrm{x}} \mathrm{Ta}_{1-\mathrm{x}} \mathrm{Co}_{2}$ phase. In cermets $20 \mathrm{Co} 1.8 \mathrm{G}$ and 20Co2.2G, only the $\mathrm{Ti}_{\mathrm{x}} \mathrm{Ta}_{1-\mathrm{x}} \mathrm{Co}_{3}$ intermetallic phase was detected. 
A similar trend was observed for the $30 \mathrm{CoyG}$ cermet series (figure $2 \mathrm{~b}$ ). Whereas for $30 \mathrm{Co} 0 \mathrm{G}$, the abovementioned cubic $\mathrm{Ti}_{\mathrm{x}} \mathrm{Ta}_{1-\mathrm{x}} \mathrm{Co}_{2}$ intermetallic compound was detected, $\mathrm{Ti}_{\mathrm{x}} \mathrm{Ta}_{1-\mathrm{x}} \mathrm{Co}_{3}$ and $\alpha$-Co were observed in the binder phase of 30Co1.4G. For $30 \mathrm{Co} 1.8 \mathrm{G}$, the relative proportion of $\alpha$-Co increased, and for $30 \mathrm{Co} 2.2 \mathrm{G}$, the binder phase consisted only of $\alpha$-Co. The small $2 \theta$ displacement $\left(0.07^{\circ}\right.$ for (111) reflection) detected in $\alpha$-Co reflections with respect to the reflections of pure cubic Co was due to small amounts of Ti and Ta dissolved in the structure, as will be discussed later in terms of the XEDS-SEM results.

All of aforementioned results suggest the following sequence of transformations in the binder with increasing graphite content: $\mathrm{Ti}_{\mathrm{x}} \mathrm{Ta}_{1-\mathrm{x}} \mathrm{Co}_{2} \rightarrow \mathrm{Ti}_{\mathrm{x}} \mathrm{Ta}_{1-\mathrm{x}} \mathrm{Co}_{3} \rightarrow \alpha-\mathrm{Co}$. This evolution of the binder towards phases richer in Co (and therefore phases poorer in $\mathrm{Ti}$ and Ta) must be related to a decreasing tendency of Ti-Ta carbonitride particles to dissolve in the molten binder during sintering in the presence of $\mathrm{C}$. The only difference between the 20CoyG and 30CoyG series was that binder phases with lower Ti and Ta contents were achieved in $30 \mathrm{CoyG}$ at lower graphite contents. For example, $\alpha$-Co was the only phase detected in $30 \mathrm{Co} 2.2 \mathrm{G}$, whereas $\mathrm{Ti}_{\mathrm{x}} \mathrm{Ta}_{1-\mathrm{x}} \mathrm{Co}_{3}$ was observed in $20 \mathrm{Co} 2.2 \mathrm{G}$. This finding is related to the amount of Co and greater number of ceramic particles that must be dissolved in 30 CoyG than in 20 CoyG to produce the same binder phase.

\subsection{Microstructure and phase stoichiometry.}

To assess the quality of the sintering process and evaluate certain microstructural parameters of interest for the mechanical properties of cermets, SEM micrographs at different magnifications were studied by IA. Representative SEM images at $2 \mathrm{kK}$ are shown in figures 3 and 4 for the $20 \mathrm{CoyG}$ and $30 \mathrm{CoyG}$ cermets, respectively. Table 2 reports the bulk density, volumetric porosity, average carbonitride particle size and 
volumetric fraction of the binder phase (BF) for cermets $20 \mathrm{CoyG}$ and $30 \mathrm{CoyG}$. A porosity of approximately 2 vol.\% was determined for all of the samples, in accordance with the similar densities observed for cermets with the same amount of Co (table 2). Cermets containing 30 wt. $\%$ Co showed higher densities as an obvious result of the higher density of Co $\left(8.9 \mathrm{~g} / \mathrm{cm}^{3}\right)$ with respect to the density of the ceramic phase $(\sim 5.6$ $\left.\mathrm{g} / \mathrm{cm}^{3}\right)$

The presence of binder occluded into the carbonitride particles was observed in both series of micrographs (figures 3 and 4), which is clear evidence that grain growth not only occurred by dissolution-reprecipitation but also by coalescence. During sintering, particles of different sizes come into contact, resulting in the formation of a neck with a grain boundary, which later migrates through small grains to form single large particles. If multiple points of contact are possible, the coalescence process can lead to the entrapment of binder within the large ceramic particles, as observed in SEM micrographs. It is well established that coalescence tends to broaden the grain size distribution $[13,21]$. This broadening is clearly visible in figures 3 and 4 , in which a bimodal size distribution can be observed with mainly small rounded particles and large faceted particles grown by coalescence. The number of small particles appears to be more important in 30CoyG cermets, perhaps caused by a higher percentage of binder resulting in less opportunity for particles to come into contact. The calculated average ceramic particle size (table 2) reflected this difference with values between 2.1-2.4 $\mu \mathrm{m}$ for the $20 \mathrm{CoyG}$ cermets and 1.3-1.7 $\mu \mathrm{m}$ for the $30 \mathrm{Coy} \mathrm{G}$ cermets.

An important effect related to microstructure was the gradual reduction in $\mathrm{BF}$ when graphite was progressively added (table 2), which is linked to the aforementioned modification of the nature of the binder phase. Because graphite reduces the dissolution of the ceramic phase into the binder, new phases $\left(\mathrm{Ti}_{\mathrm{x}} \mathrm{Ta}_{1-\mathrm{x}} \mathrm{Co}_{3}\right.$ and $\left.\alpha-\mathrm{Co}\right)$ with lower $\mathrm{Ti}$ 
and Ta contents were formed, which induced the evolution observed in BF. Logically, $\mathrm{BF}$ was higher in $30 \mathrm{Coy} \mathrm{G}$ due to the higher Co content in the nominal composition. Only $20 \mathrm{Co} 0 \mathrm{G}$ and $20 \mathrm{Co} 0.5 \mathrm{G}$ showed no differences in BF because both cermets had identical binder phases (figure 2). The theoretical BF value calculated for a cermet with a nominal composition 70 wt. $\% \mathrm{Ti}_{0.95} \mathrm{Ta}_{0.05} \mathrm{C}_{0.5} \mathrm{~N}_{0.5}-30$ wt.\% Co agreed well with that determined by IA for $30 \mathrm{Co} 2.2 \mathrm{G}$ containing only $\alpha$-Co as the binder phase ( 23.7 vol. $\%$ and 22.8 vol.\%, respectively).

Semiquantitative XEDS-SEM analyses (table 3) were carried out to obtain information about the $\mathrm{Ti}$, Ta and Co contents in the ceramic and binder phases. For all cermets, ceramic particles presented $\mathrm{Ti}$ and $\mathrm{Ta}$ atomic percentages corresponding to the nominal starting composition. Mean values of $\mathrm{Ti}=95.4 \pm 0.4$ at. $\%$ and $\mathrm{Ta}=4.6 \pm 0.4$ at.\% were observed, which indicated that there was no variation in chemical composition during sintering. Furthermore, binder compositions (table 3) confirmed the reduction in the $\mathrm{Ti}$ and $\mathrm{Ta}$ contents (from approximately 35 at.\% to 10 at.\%) in the binder as the graphite content increased, and the results were in good agreement with the phases identified by XRD (figure 2). Although the accuracy of measurements and the interference from neighbouring phases have to be taken into account, this trend (enrichment in Co) was observed even for the same phase. For instance, in the $\mathrm{Ti}_{\mathrm{x}} \mathrm{Ta}_{1-}$ ${ }_{\mathrm{x}} \mathrm{Co}_{3}$ intermetallic, $\mathrm{Co} /(\mathrm{Ti}+\mathrm{Ta})$ ratios of 2.4 at.\%, 2.9 at.\%, 3.3 at.\% and 4.0 at.\% were obtained for $20 \mathrm{Co} 1 \mathrm{G}, 20 \mathrm{Co} 1.4 \mathrm{G}, 20 \mathrm{Co} 1.8 \mathrm{G}$ and $20 \mathrm{Co} 2.2 \mathrm{G}$, respectively. $\mathrm{A} \mathrm{Co} /(\mathrm{Ti}+\mathrm{Ta})$ ratio different from the stoichiometric value of 3 should not be surprising based on the binary phase diagrams of Ti-Co and Ta-Co [47], which indicate that the phase possesses a non-stoichiometric compositional range.

To corroborate the structure and chemical composition of the binder phases observed when graphite was added, 20Co1.8G and 30Co1.8G cermets were studied by 
TEM using SAED (figure 5) and XEDS-TEM (table 3). Only a binder phase with cubic structure and Pm-3m space group symmetry was observed in the 20Co1.8G cermet; three SAED patterns oriented along the [101], [112] and [111] zone axes are shown in figure 5a. By XEDS-TEM (table 3), a stoichiometry close to $\mathrm{Ti}_{\mathrm{x}} \mathrm{Ta}_{1-\mathrm{x}} \mathrm{Co}_{3}$ intermetallic phase was confirmed. For the 30Co1.8G cermet (figure 5b), two different binder phases were detected, corresponding to cubic phases with Pm-3m (SAED patterns along [103] and [101] zone axes) and Fm-3m (SAED patterns along [112], [101] and [111] zone axes) space group symmetries, which according to XEDS-TEM were associated with $\mathrm{Ti}_{\mathrm{x}} \mathrm{Ta}_{1-\mathrm{x}} \mathrm{Co}_{3}$ and $\alpha-\mathrm{Co}$, respectively. The results obtained by XEDS-SEM and XEDSTEM were in close agreement for the two cermets (table 3).

\subsection{Mechanical behaviour.}

Vickers hardness values for 20CoyG and 30CoyG cermets are shown in table 4 . These hardness values are of the same order of magnitude as those reported for cermets with similar binder contents [5, 49]. A nearly constant value of approximately $14 \mathrm{GPa}$ was obtained in the 20 CoyG cermets, whereas a small decrease was observed in the 30CoyG cermets when the amount of graphite was increased. This behaviour could be considered inconsistent with the reduction of the $\mathrm{BF}$ content because of the corresponding higher ceramic phase content is expected to produce higher hardness. However, the variation in the composition of the binder phase that accompanies the addition of graphite must also be taken into account to explain the evolution of mechanical properties. In this respect, the hardness values in table 4 can be explained if it is assumed that not only $\alpha$-Co but also the $\mathrm{Ti}_{\mathrm{x}} \mathrm{Ta}_{1-\mathrm{x}} \mathrm{Co}_{3}$ intermetallic phase are more ductile [50], and consequently less hard, than $\mathrm{Ti}_{\mathrm{x}} \mathrm{Ta}_{1-\mathrm{x}} \mathrm{Co}_{2}$. 
To confirm this hypothesis and determine the mechanical properties of different phases acting as binder, nanoindentation tests were conducted in cermets $20 \mathrm{Co} 0 \mathrm{G}$, 20Co1.8G and 30Co2.2G containing $\mathrm{Ti}_{\mathrm{x}} \mathrm{Ta}_{1-\mathrm{x}} \mathrm{Co}_{2}, \mathrm{Ti}_{\mathrm{x}} \mathrm{Ta}_{1-\mathrm{x}} \mathrm{Co}_{3}$ or $\alpha-\mathrm{Co}$, respectively, as the sole binder phase. The size of indentation marks (figures 6a-c), their $\mathrm{H}$ values (table 5) and the characteristic load-displacement curves (figure 6d) confirmed that hardness decreases in the order: $\mathrm{Ti}_{\mathrm{x}} \mathrm{Ta}_{1-\mathrm{x}} \mathrm{Co}_{2}>\mathrm{Ti}_{\mathrm{x}} \mathrm{Ta}_{1-\mathrm{x}} \mathrm{Co}_{3}>\alpha$-Co. A similar trend was also obtained for $\mathrm{E}$ (table 5), with the highest value observed for $\mathrm{Ti}_{\mathrm{x}} \mathrm{Ta}_{1-\mathrm{x}} \mathrm{Co}_{2}$ and the lowest one for $\alpha$-Co. The $\mathrm{H}$ and $\mathrm{E}$ values of $\mathrm{Ti}_{\mathrm{x}} \mathrm{Ta}_{1-\mathrm{x}} \mathrm{Co}_{3}$ and $\alpha$-Co were similar to those observed for constrained Co in WC-Co hard metals [51, 52] and therefore characteristic of ductile metal phases. However, the high $\mathrm{H}$ and $\mathrm{E}$ values observed for $\mathrm{Ti}_{\mathrm{x}} \mathrm{Ta}_{1-\mathrm{x}} \mathrm{Co}_{2}$, closer to those observed in ceramics, suggests that this phase is fragile. $\mathrm{H}$ and $\mathrm{E}$ were also determined for the ceramic particles in these cermets (figure 7 and table 5), and as expected, similar mechanical properties and load-displacement curves were obtained because the carbonitride chemical composition was identical in the three cermets.

The modification of the nature of the binder phase had the most remarkable effect on the indentation fracture toughness of the cermets, as shown in table 4. Cermets without graphite (20Co0G and 30Co0G) showed low toughness due to the presence of the hard and brittle $\mathrm{Ti}_{\mathrm{x}} \mathrm{Ta}_{1-\mathrm{x}} \mathrm{Co}_{2}$ intermetallic compound. As the amount of graphite was increased in the $20 \mathrm{Coy} \mathrm{G}$ cermets and $\mathrm{Ti}_{\mathrm{x}} \mathrm{Ta}_{1-\mathrm{x}} \mathrm{Co}_{2}$ was continually substituted by the more ductile $\mathrm{Ti}_{\mathrm{x}} \mathrm{Ta}_{1-\mathrm{x}} \mathrm{Co}_{3}$ intermetallic, a significant increase in $\mathrm{K}_{\mathrm{IC}}$ was observed, reaching maximum values in those cermets containing only $\mathrm{Ti}_{\mathrm{x}} \mathrm{Ta}_{1-\mathrm{x}} \mathrm{Co}_{3}$ as binder. The same trend was observed in the $30 \mathrm{Coy} G$ cermets, in which the disappearance of $\mathrm{Ti}_{\mathrm{x}} \mathrm{Ta}_{1-}$ ${ }_{x} \mathrm{Co}_{2}$ and the formation of $\mathrm{Ti}_{\mathrm{x}} \mathrm{Ta}_{1-\mathrm{x}} \mathrm{Co}_{3}$ and $\alpha$-Co were also accompanied by an increase in $\mathrm{K}_{\mathrm{IC}}$. As previously indicated with respect to the hardness results, the observed improvement in $\mathrm{K}_{\mathrm{IC}}$ becomes more significant if the $\mathrm{BF}$ decrease is considered because 
it is the binder phase that confers toughness to cermets. The maximum values observed for the two series were $8.8 \mathrm{MPam}^{1 / 2}$ for $20 \mathrm{Co} 1.8 \mathrm{G}$ and $10.7 \mathrm{MPam}^{1 / 2}$ for $30 \mathrm{Co} 1.8 \mathrm{G}$. The higher $\mathrm{K}_{\mathrm{IC}}$ observed in $30 \mathrm{Co} 1.8 \mathrm{G}$ was due to the higher proportion of binder, and no significant differences were observed between cermets containing $\mathrm{Ti}_{\mathrm{x}} \mathrm{Ta}_{1-\mathrm{x}} \mathrm{Co}_{3}$ or $\alpha$ Co. This finding is in accord with the nanoindentation results, which showed that both phases have similar mechanical properties.

\section{Conclusions.}

Complete solid solution $(\mathrm{Ti}, \mathrm{Ta})(\mathrm{C}, \mathrm{N})-\mathrm{Co}$ cermets were developed by exploiting the ability of the MSR mechanochemical process to yield titanium-tantalum carbonitride solid solutions. The presence of graphite in the binder as a sintering additive was necessary to reduce the extent of the dissolution of carbonitride ceramic particles during liquid phase sintering and avoid the formation of undesirable intermetallic compounds after cooling. As graphite was progressively added, a continuous decrease in the contents of $\mathrm{Ti}$ and $\mathrm{Ta}$ in the binder was observed, resulting in the formation of phases richer in $\mathrm{Co}$, from $\mathrm{Ti}_{\mathrm{x}} \mathrm{Ta}_{1-\mathrm{x}} \mathrm{Co}_{2}$ (without graphite) to $\mathrm{Ti}_{\mathrm{x}} \mathrm{Ta}_{1-\mathrm{x}} \mathrm{Co}_{3}$ and finally to $\alpha$-Co.

Changes in the nature of the binder had a significant effect on the mechanical properties of the cermets, particularly their toughness. The formation of ductile phases, $\mathrm{Ti}_{\mathrm{x}} \mathrm{Ta}_{1-\mathrm{x}} \mathrm{Co}_{3}$ and $\alpha$-Co, instead of brittle $\mathrm{Ti}_{\mathrm{x}} \mathrm{Ta}_{1-\mathrm{x}} \mathrm{Co}_{2}$ produced an outstanding improvement in toughness, while maintaining high hardness values, such that it was possible to reach an optimal combination of both properties.

\section{Acknowledgments}


This work was supported by the Spanish government under grant No. MAT2011-22981, which was financed in part by the European Regional Development Fund of 2007-2013. E. Chicardi and J. M. Córdoba were supported by the CSIC through JAE-Pre and JAE-Doc grants, respectively, which are financed in part by the European Social Fund (ESF). The authors want to thank the laboratory technician Mercedes Sánchez for her assistance with the Vickers hardness tests.

\section{References.}

[1] H. Pastor, Titanium-carbonitride-based hard alloys for cutting tools, Materials Science and Engineering 105-106 (1988) 401-409.

[2] J.M. Córdoba, M.D. Alcalá, M.A. Avilés, M.J. Sayagués, F.J. Gotor, New production of TiCxN1-x-based cermets by one step mechanically induced self-sustaining reaction: Powder synthesis and pressureless sintering, Journal of the European Ceramic Society 28 (2008) 20852098.

[3] S. Zhang, Titanium carbonitride-based cermets: processes and properties, Materials Science and Engineering A 163 (1993) 141-148.

[4] J.M. Cordoba, E. Chicardi, F.J. Gotor, Liquid-phase sintering of Ti(C,N)-based cermets. The effects of binder nature and content on the solubility and wettability of hard ceramic phases, Journal of Alloys and Compounds 559 (2013) 34-38.

[5] W.M. Daoush, H.S. Park, K.H. Lee, S.F. Moustafa, S.H. Hong, Effect of binder compositions on microstructure, hardness and magnetic properties of $(\mathrm{Ta}, \mathrm{Nb}) \mathrm{C}-\mathrm{Co}$ and $(\mathrm{Ta}, \mathrm{Nb}) \mathrm{C}-\mathrm{Ni}$ cemented carbides, International Journal of Refractory Metals and Hard Materials 27 (2009) 669-675.

[6] P. Ettmayer, Hardmetals and cermets, Annual Review of Materials Science 19 (1989) 145164.

[7] P. Ettmayer, H. Kolaska, W. Lengauer, K. Dreyer, Ti(C,N) Cermets - Metallurgy and Properties, International Journal of Refractory Metals and Hard Materials 13 (1995) 343.

[8] E. Chicardi, Y. Torres, J.M. Cordoba, P. Hvizdos, F.J. Gotor, Effect of tantalum content on the microstructure and mechanical behavior of cermets based on (TixTa1-x)(C0.5N0.5) solid solutions, Materials \& Design 53 (2014) 435-444.

[9] J. Wang, Y. Liu, P. Zhang, J. Ye, M. Tu, Effect of VC and nano-TiC addition on the microstructure and properties of micrometer grade $\mathrm{Ti}(\mathrm{CN})$-based cermets, Materials and Design 30 (2009) 2222-2226.

[10] W.T. Kwon, J.S. Park, S.W. Kim, S. Kang, Effect of WC and group IV carbides on the cutting performance of $\mathrm{Ti}(\mathrm{C}, \mathrm{N})$ cermet tools, International Journal of Machine Tools and Manufacture 44 (2004) 341-346.

[11] X. Zhang, N. Liu, Effects of ZrC on microstructure, mechanical properties and thermal shock resistance of TiC-ZrC-Co-Ni cermets, Materials Science and Engineering a-Structural Materials Properties Microstructure and Processing 561 (2013) 270-276.

[12] G. Zhu, Y. Liu, J. Ye, Influence of Ce-Co pre-alloyed powder addition on the microstructure and mechanical properties of $\mathrm{Ti}(\mathrm{C}, \mathrm{N})$-based cermets, International Journal of Refractory Metals and Hard Materials 37 (2013) 134-141. 
[13] I. Iparraguirre, N. Rodriguez, F. Ibarreta, R. Martinez, J.M. Sanchez, Effect of the Cr content on the sintering behaviour of TiCN-WC-Ni-Cr3C2 powder mixtures, Int. J. Refract. Met. Hard Mat. 43 (2014) 125-131.

[14] Y. Li, P. Bai, Y. Wang, J. Hu, Z. Guo, Effect of Ni contents on the microstructure and mechanical properties of $\mathrm{TiC}-\mathrm{Ni}$ cermets obtained by direct laser fabrication, International Journal of Refractory Metals and Hard Materials 27 (2009) 552-555.

[15] E.B. Clark, B. Roebuck, Extending the application areas for titanium carbonitride cermets, International Journal of Refractory Metals and Hard Materials 11 (1992) 23-33.

[16] H. Pastor, Present status and development of tool materials: part 1 cutting tools, International Journal of Refractory Metals and Hard Materials 6 (1987) 196-209.

[17] T. Matsuda, H. Matsubara, Synthesis of titanium carbonitride nano-powder by carbothermal reduction of TiO2, Int. J. Refract. Met. Hard Mat. 42 (2014) 1-8.

[18] S.Y. Ahn, S. Kang, Formation of core/rim structures in Ti(C,N)-WC-Ni cermets via a dissolution and precipitation process, Journal of the American Ceramic Society 83 (2000) 14891494.

[19] J.W. Kim, S.Y. Ahn, S. Kang, Effect of the complete solid-solution phase on the microstructure of Ti(CN)-based cermet, Int. J. Refract. Met. Hard Mat. 27 (2009) 224-228.

[20] Y.K. Kim, J.H. Shim, Y.W. Cho, H.S. Yang, J.K. Park, Mechanochemical synthesis of nanocomposite powder for ultrafine ( $\mathrm{Ti}, \mathrm{Mo}) \mathrm{C}-\mathrm{Ni}$ cermet without core-rim structure, International Journal of Refractory Metals and Hard Materials 22 (2004) 193-196.

[21] E. Chicardi, J.M. Córdoba, M.J. Sayagués, F.J. Gotor, Absence of the core-rim microstructure in TixTa1-XCyN1-y-based cermets developed from a pre-sintered carbonitride master alloy, International Journal of Refractory Metals and Hard Materials 33 (2012) 38-43.

[22] L. Takacs, Self-sustaining reactions induced by ball milling, Progress in Materials Science 47 (2002) 355-414.

[23] J.M. Córdoba, M.A. Avilés, M.J. Sayagués, M.D. Alcalá, F.J. Gotor, Synthesis of complex carbonitride powders TiyMT1-yCxN1-x (MT:Zr,V,Ta,Hf) via a mechanically induced selfsustaining reaction, Journal of Alloys and Compounds 482 (2009) 349-355.

[24] J.M. Córdoba, M.J. Sayagués, M.D. Alcalá, F.J. Gotor, Monophasic nanostructured powders of niobium, tantalum, and hafnium carbonitrides synthesized by a mechanically induced selfpropagating reaction, Journal of the American Ceramic Society 90 (2007) 381-387.

[25] A. Borrell, M. Dolores Salvador, V. Garcia-Rocha, A. Fernandez, E. Chicardi, F.J. Gotor, Spark plasma sintering of TiyNb1-yCxN1-x monolithic ceramics obtained by mechanically induced self-sustaining reaction, Materials Science and Engineering a-Structural Materials Properties Microstructure and Processing 543 (2012) 173-179.

[26] J.M. Cordoba, E. Chicardi, F.J. Gotor, Development of multicomponent-multiphase materials based on $(\mathrm{Ti}, \mathrm{Ta}, \mathrm{Nb}) \mathrm{CxN} 1-\mathrm{x}$ carbonitride solid solutions, Chemical Engineering Journal 192 (2012) 58-66.

[27] R. De Silva, P. Plescia, A. Bianco, L. De Notaris, Industrial planetary mill for producing nanomaterials using mechanochemical processes, European Patent, 2010.

[28] V.G. Kochnev, Planetary mill, Russian Federation patent, 1992.

[29] M.J. Sayagués, M.A. Avilés, J.M. Córdoba, M.D. Alcalá, F.J. Gotor, Microstructural characterization of ceramic-intermetallic composites using TEM related techniques, Journal of the European Ceramic Society 30 (2010) 1765-1774.

[30] J. Zackrisson, A. Larsson, H.O. Andrén, Microstructure of the Ni binder phase in a TicMo2C-Ni cermet, Micron 32 (2001) 707-712.

[31] N. Durlu, Titanium carbide based composites for high temperature applications, Journal of the European Ceramic Society 19 (1999) 2415-2419.

[32] M. Alvarez, J.M. Sánchez, Spark plasma sintering of Ti(C, N) cermets with intermetallic binder phases, International Journal of Refractory Metals and Hard Materials 25 (2007) 107118. 
[33] I. Borgh, P. Hedstrom, A. Borgenstam, J. Agren, J. Odqvist, Effect of carbon activity and powder particle size on WC grain coarsening during sintering of cemented carbides, Int. J. Refract. Met. Hard Mat. 42 (2014) 30-35.

[34] Y. Wang, M. Heusch, S. Lay, C.H. Allibert, Microstructure evolution in the cemented carbides WC-Col. Effect of the C/W ratio on the morphology and defects of the WC grains, Physica Status Solidi a-Applied Research 193 (2002) 271-283.

[35] M. Fukuhara, H. Mitani, Mechanism of grain growth in Ti(C,N)-Ni sintered alloys, Powder Metallurgy 25 (1982) 62-68.

[36] Y. Li, N. Liu, X. Zhang, C. Rong, Effect of carbon content on the microstructure and mechanical properties of ultra-fine grade $(\mathrm{Ti}, \mathrm{W})(\mathrm{C}, \mathrm{N})$-Co cermets, Journal of Materials Processing Technology 206 (2008) 365-373.

[37] Y. Zheng, W.J. Liu, S.X. Wang, W.H. Xiong, Effect of carbon content on the microstructure and mechanical properties of $\mathrm{Ti}(\mathrm{C}, \mathrm{N})$-based cermets, Ceramics International 30 (2004) 21112115.

[38] L. Chen, W. Lengauer, P. Ettmayer, K. Dreyer, H.W. Daub, D. Kassel, Fundamentals of liquid phase sintering for modern cermets and functionally graded cemented carbonitrides (FGCC), International Journal of Refractory Metals and Hard Materials 18 (2000) 307-322.

[39] F.J. Gotor, M. Achimovicova, C. Real, P. Balaz, Influence of the milling parameters on the mechanical work intensity in planetary mills, Powder Technol. 233 (2013) 1-7.

[40] E. Chicardi, F.J. Gotor, J.M. Córdoba, Enhanced oxidation resistance of Ti(C,N)-based cermets containing Ta, Corrosion Science 84 (2014) 11-20.

[41] K. Niihara, A fracture-mechanics analysis of indentation-induced Palmqvist crack in ceramics, Journal of Materials Science Letters 2 (1983) 221-223.

[42] R. Spiegler, S. Schmauder, L. Sigl, Fracture Toughness Evaluation of WC-Co Alloys by Indentation Testing, Journal of Hard Materials 1 (1990) 174-158.

[43] R. Warren, H. Matzke, Indentation Testing of a Broad Range of Cemented Carbides, in: R.K. Viswanadham, D.J. Rowcliffe, J. Gurland (Eds.) Science of Hard Materials, Springer US1983, pp. 563-582.

[44] W.C. Oliver, G.M. Pharr, An improved technique for determining hardness and elasticmodulus using load and displacement sensing indentation experiments., J. Mater. Res. 7 (1992) 1564-1583.

[45] E. Chicardi, J.M. Córdoba, M.J. Sayagués, F.J. Gotor, Inverse core-rim microstructure in $(\mathrm{Ti}, \mathrm{Ta})(\mathrm{C}, \mathrm{N})$-based cermets developed by a mechanically induced self-sustaining reaction, International Journal of Refractory Metals and Hard Materials 31 (2012) 39-46.

[46] J.Y. Huang, HRTEM and EELS studies of defects structure and amorphous-like graphite induced by ball-milling, Acta Materialia 47 (1999) 1801-1808.

[47] O.H. Baker H, Alloy Phase Diagrams, ASM Handbook.1992.

[48] M. Jiang, G. Saren, S.Y. Yang, H.X. Li, S.M. Hao, Phase equilibria in Co-rich region of Co-TiTa system, Trans. Nonferrous Met. Soc. China 21 (2011) 2391-2395.

[49] Y. Liu, Y. Jin, H. Yu, J. Ye, Ultrafine $(T i, M)(C, N)$-based cermets with optimal mechanical properties, International Journal of Refractory Metals and Hard Materials 29 (2011) 104-107.

[50] W.W. Xu, J.J. Han, Z.W. Wang, C.P. Wang, Y.H. Wen, X.J. Liua, Z.Z. Zhu, Thermodynamic, structural and elastic properties of $\operatorname{Co} 3 \mathrm{X}(\mathrm{X}=\mathrm{Ti}, \mathrm{Ta}, \mathrm{W}, \mathrm{V}, \mathrm{Al})$ compounds from first-principles calculations, Intermetallics 32 (2013) 303-311.

[51] A. Duszova, R. Halgas, M. Blanda, P. Hvizdos, F. Lofaj, J. Dusza, J. Morgiel, Nanoindentation of WC-Co hardmetals, Journal of the European Ceramic Society 33 (2013) 2227-2232.

[52] V. Bonache, E. Rayon, M.D. Salvador, D. Busquets, Nanoindentation study of WC-12Co hardmetals obtained from nanocrystalline powders: Evaluation of hardness and modulus on individual phases, Materials Science and Engineering a-Structural Materials Properties Microstructure and Processing 527 (2010) 2935-2941. 


\section{FIGURE CAPTIONS.}

Figure 1. X-ray powder diffraction diagrams of the Ti-Ta carbonitride solid solution obtained via the MSR process (a) and the powdered cermets 20Co1.8G (b) and 30Co1.8G (c) after mixing the carbonitride ceramic phase with Co and graphite. $(\bullet)$ $\mathrm{Ti}_{0.95} \mathrm{Ta}_{0.05} \mathrm{C}_{0.5} \mathrm{~N}_{0.5} ;(\boldsymbol{\vee})$ Hexagonal Co.

Figure 2. X-ray powder diffraction diagrams of $20 \operatorname{CoyG}$ (a) and $30 \operatorname{CoyG}$ (b) sintered cermets. (•) $\mathrm{Ti}_{0.95} \mathrm{Ta}_{0.05} \mathrm{C}_{0.5} \mathrm{~N}_{0.5} ;(\boldsymbol{\nabla})$ Cubic $\mathrm{Ti}_{\mathrm{x}} \mathrm{Ta}_{1-\mathrm{x}} \mathrm{Co}_{2} ;(\bullet)$ Hexagonal $\mathrm{Ti}_{\mathrm{x}} \mathrm{Ta}_{1-\mathrm{x}} \mathrm{Co}_{2} ;(\bullet)$ $\mathrm{Ti}_{\mathrm{x}} \mathrm{Ta}_{1-\mathrm{x}} \mathrm{Co}_{3} ;(\boldsymbol{\vee}) \alpha-\mathrm{Co}$.

Figure 3. SEM micrographs of $20 \mathrm{Coy} \mathrm{G}$ cermets.

Figure 4. SEM micrographs of $30 \mathrm{Coy} \mathrm{G}$ cermets.

Figure 5. SAED patterns of binder phases in cermets 20Co1.8G (a) and 30Co1.8G (b). Continuous line $=\mathrm{Ti}_{\mathrm{x}} \mathrm{Ta}_{1-\mathrm{x}} \mathrm{Co}_{3} ;$ dotted line $=\alpha-\mathrm{Co}$.

Figure 6. Nanoindentations in binder of cermets (a) $20 \mathrm{Co} 0 \mathrm{G}$ (binder phase: $\mathrm{Ti}_{\mathrm{x}} \mathrm{Ta}_{1-}$ ${ }_{x} \mathrm{Co}_{2}$ ), (b) 20Co1.8G (binder phase: $\mathrm{Ti}_{\mathrm{x}} \mathrm{Ta}_{1-\mathrm{x}} \mathrm{Co}_{3}$ ) and (c) 30Co2.2G (binder phase: $\alpha$ Co). (d) Characteristic load-displacement curves of indents in these binder phases.

Figure 7. Nanoindentations in ceramic particles of cermets (a) 20Co0G, (b) 20Co1.8G and (c) 30Co2.2G. (d) Characteristic load-displacement curves of indents in these ceramic particles. 
Table 1. Nominal composition of cermets.

\begin{tabular}{|c|c|c|c|}
\hline Cermet & wt. $\% \mathrm{Ti}_{0.95} \mathrm{Ta}_{0.05} \mathrm{C}_{0.5} \mathrm{~N}_{0.5}$ & wt. \% Co & wt. \% G \\
\hline 20Co0G & \multirow{6}{*}{80} & \multirow{6}{*}{20} & 0 \\
\hline 20Co0.5G & & & 0.5 \\
\hline 20Co1G & & & 1.0 \\
\hline 20Co1.4G & & & 1.4 \\
\hline 20Co1.8G & & & 1.8 \\
\hline 20Co2.2G & & & 2.2 \\
\hline 30Co0G & \multirow{4}{*}{70} & \multirow{4}{*}{30} & 0 \\
\hline 30Co1.4G & & & 1.4 \\
\hline 30Co1.8G & & & 1.8 \\
\hline $30 \mathrm{Co} 2.2 \mathrm{G}$ & & & 2.2 \\
\hline
\end{tabular}

Table 2. Bulk density ( $\rho)$, porosity (p), average carbonitride particle size (d) and volumetric fraction of binder phase (BF) for cermets $20 \mathrm{CoyG}$ and $30 \mathrm{Coy} \mathrm{G}$.

\begin{tabular}{|c|c|c|c|c|}
\hline Cermet & $\rho\left(\mathbf{g} / \mathrm{cm}^{\mathbf{3}}\right)$ & $\mathbf{p}(\boldsymbol{\%})$ & $\mathbf{d}(\boldsymbol{\mu m})$ & BF $(\boldsymbol{\%})$ \\
\hline 20Co0G & $5.97 \pm 0.03$ & $2.1 \pm 0.4$ & $2.4 \pm 0.8$ & $22.0 \pm 1.2$ \\
\hline 20Co0.5G & $5.92 \pm 0.06$ & $2.3 \pm 0.6$ & $2.3 \pm 0.9$ & $22.1 \pm 0.8$ \\
\hline 20Co1G & $5.94 \pm 0.04$ & $2.4 \pm 0.3$ & $2.4 \pm 1.1$ & $20.7 \pm 0.6$ \\
\hline 20Co1.4G & $5.95 \pm 0.02$ & $2.1 \pm 0.6$ & $2.2 \pm 1.2$ & $19.3 \pm 1.1$ \\
\hline 20Co1.8G & $5.93 \pm 0.03$ & $2.2 \pm 0.2$ & $2.1 \pm 0.9$ & $18.3 \pm 0.9$ \\
\hline 20Co2.2G & $5.91 \pm 0.05$ & $2.2 \pm 0.3$ & $2.2 \pm 0.8$ & $16.6 \pm 1.1$ \\
\hline 30Co0G & $6.28 \pm 0.07$ & $2.2 \pm 0.3$ & $1.7 \pm 1.0$ & $33.4 \pm 1.3$ \\
\hline 30Co1.4G & $6.15 \pm 0.03$ & $2.3 \pm 0.6$ & $1.3 \pm 0.9$ & $25.4 \pm 0.5$ \\
\hline 30Co1.8G & $6.12 \pm 0.06$ & $2.3 \pm 0.5$ & $1.5 \pm 1,1$ & $23.9 \pm 1.2$ \\
\hline 30Co2.2G & $6.06 \pm 0.08$ & $1.8 \pm 0.3$ & $1.7 \pm 0.9$ & $22.8 \pm 0.8$ \\
\hline
\end{tabular}


Table 3. Ti, Ta and Co contents (at.\%) in ceramic particles and binder for 20CoyG and 30CoyG cermets determined by XEDS-SEM and XEDS-TEM and corresponding binder phase in agreement with these contents and XRD results.

\begin{tabular}{|c|c|c|c|c|c|c|c|}
\hline \multicolumn{8}{|c|}{ XEDS-SEM } \\
\hline \multirow{2}{*}{ Cermet } & \multicolumn{2}{|c|}{ Ceramic } & \multicolumn{5}{|c|}{ Binder } \\
\hline & $\mathbf{T i}$ & Ta & Ti & $\mathbf{T a}$ & Co & $\mathrm{Co} /(\mathrm{Ti}+\mathrm{Ta})$ & XRD Phase \\
\hline $20 \mathrm{CoOG}$ & 95.2 & 4.8 & 28.0 & 6.6 & 65.4 & 1.9 & $\mathrm{Ti}_{\mathrm{x}} \mathrm{Ta}_{1-\mathrm{x}} \mathrm{Co}_{2}(\mathrm{c})$ \\
\hline $20 \mathrm{Co} 0.5 \mathrm{G}$ & 95.4 & 4.6 & 28.6 & 4.9 & 66.5 & 2.0 & $\mathrm{Ti}_{\mathrm{x}} \mathrm{Ta}_{1-\mathrm{x}} \mathrm{Co}_{2}(\mathrm{c})$ \\
\hline 20Co1G & 96.0 & 4.0 & $\begin{array}{l}29.4 \\
28.1\end{array}$ & $\begin{array}{l}2.0 \\
1.6\end{array}$ & $\begin{array}{l}68.6 \\
70.3\end{array}$ & $\begin{array}{l}2.2 \\
2.4\end{array}$ & $\begin{array}{l}\mathrm{Ti}_{\mathrm{x}} \mathrm{Ta}_{1-\mathrm{x}} \mathrm{Co}_{2}(\mathrm{~h}) \\
\mathrm{Ti}_{\mathrm{x}} \mathrm{Ta}_{1-\mathrm{x}} \mathrm{Co}_{3}\end{array}$ \\
\hline 20Co1.4G & 96.0 & 4.0 & $\begin{array}{l}31.6 \\
24.5 \\
\end{array}$ & $\begin{array}{l}1.6 \\
1.1 \\
\end{array}$ & $\begin{array}{l}66.9 \\
74.4 \\
\end{array}$ & $\begin{array}{l}2.0 \\
2.9 \\
\end{array}$ & $\begin{array}{l}\mathrm{Ti}_{\mathrm{x}} \mathrm{Ta}_{1-\mathrm{x}} \mathrm{Co}_{2}(\mathrm{c}) \\
\mathrm{Ti}_{\mathrm{x}} \mathrm{Ta}_{1-\mathrm{x}} \mathrm{Co}_{3}\end{array}$ \\
\hline 20Co1.8G & 95.5 & 4.5 & 22.4 & 1.0 & 76.6 & 3.3 & $\mathrm{Ti}_{\mathrm{x}} \mathrm{Ta}_{1-\mathrm{x}} \mathrm{Co}_{3}$ \\
\hline $20 \mathrm{Co} 2.2 \mathrm{G}$ & 95.3 & 4.7 & 17.3 & 2.8 & 79.9 & 4.1 & $\mathrm{Ti}_{\mathrm{x}} \mathrm{Ta}_{1-\mathrm{x}} \mathrm{Co}_{3}$ \\
\hline 30Co0G & 95.4 & 4.6 & 33.0 & 4.0 & 63.0 & 1.7 & $\mathrm{Ti}_{\mathrm{x}} \mathrm{Ta}_{1-\mathrm{x}} \mathrm{Co}_{2}(\mathrm{c})$ \\
\hline 30Co1.4G & 94.8 & 5.2 & $\begin{array}{l}21.7 \\
14.5 \\
\end{array}$ & $\begin{array}{l}2.9 \\
3.2 \\
\end{array}$ & $\begin{array}{l}75.4 \\
83.3\end{array}$ & $\begin{array}{l}3.1 \\
4.7 \\
\end{array}$ & $\begin{array}{l}\mathrm{Ti}_{\mathrm{x}} \mathrm{Ta}_{1-\mathrm{x}} \mathrm{Co}_{3} \\
\alpha-\mathrm{Co}\end{array}$ \\
\hline 30Co1.8G & 95.0 & 5.0 & $\begin{array}{l}19.2 \\
11.2 \\
\end{array}$ & $\begin{array}{l}1.9 \\
2.1 \\
\end{array}$ & $\begin{array}{l}78.9 \\
86.7\end{array}$ & $\begin{array}{l}3.7 \\
6.5 \\
\end{array}$ & $\begin{array}{l}\mathrm{Ti}_{\mathrm{x}} \mathrm{Ta}_{1-\mathrm{x}} \mathrm{Co}_{3} \\
\alpha-\mathrm{Co}\end{array}$ \\
\hline $30 \mathrm{Co} 2.2 \mathrm{G}$ & 96.0 & 4.0 & 8.7 & 1.6 & 89.7 & 8.7 & $\alpha-\mathrm{Co}$ \\
\hline \multicolumn{8}{|c|}{ XEDS-TEM } \\
\hline 20Co1.8G & 95.3 & 4.7 & 21.8 & 1.3 & 76.9 & 3.3 & $\mathrm{Ti}_{\mathrm{x}} \mathrm{Ta}_{1-\mathrm{x}} \mathrm{Co}_{3}$ \\
\hline 30Co1.8G & 95.1 & 4.9 & $\begin{array}{l}18.6 \\
11.4 \\
\end{array}$ & $\begin{array}{l}2.9 \\
1.7\end{array}$ & $\begin{array}{l}78.5 \\
86.9\end{array}$ & $\begin{array}{l}3.7 \\
6.6\end{array}$ & $\begin{array}{l}\mathrm{Ti}_{\mathrm{x}} \mathrm{Ta}_{1-\mathrm{x}} \mathrm{Co}_{3} \\
\alpha-\mathrm{Co}\end{array}$ \\
\hline
\end{tabular}


Table 4. Vickers hardness $\left(\mathrm{HV}_{5}\right)$ and indentation fracture toughness $\left(\mathrm{K}_{\mathrm{IC}}\right)$ for cermets 20CoyG and 30CoyG.

\begin{tabular}{|l|c|c|}
\hline Cermet & $\mathrm{HV}_{\mathbf{5}}(\mathbf{G P a})$ & $\mathrm{K}_{\mathrm{IC}}\left(\mathbf{M P a} \cdot \mathbf{m}^{\mathbf{1} / \mathbf{2}}\right)$ \\
\hline 20Co0G & $14.5 \pm 0.5$ & $3.9 \pm 0.2$ \\
\hline 20Co0.5G & $15.3 \pm 0.4$ & $4.1 \pm 0.4$ \\
\hline 20Co1G & $14.1 \pm 0.7$ & $4.8 \pm 0.3$ \\
\hline 20Co1.4G & $14.1 \pm 0.3$ & $6.7 \pm 0.3$ \\
\hline 20Co1.8G & $13.8 \pm 0.2$ & $8.8 \pm 0.2$ \\
\hline 20Co2.2G & $14.4 \pm 0.8$ & $8.3 \pm 0.2$ \\
\hline 30Co0G & $13.9 \pm 1.0$ & $4.1 \pm 0.5$ \\
\hline 30Co1.4G & $12.0 \pm 0.5$ & $10.6 \pm 0.4$ \\
\hline 30Co1.8G & $12.0 \pm 0.5$ & $10.7 \pm 0.6$ \\
\hline 30Co2.2G & $10.3 \pm 0.7$ & $10.4 \pm 0.7$ \\
\hline
\end{tabular}

Table 5. Nanohardness $(\mathrm{H})$ and Young's modulus (E) for binder and ceramic phases in 20Co0G, 20Co1.8G and 30Co2.2G cermets.

\begin{tabular}{|c|c|c|c|c|c|c|}
\hline \multirow{2}{*}{ Cermet } & \multicolumn{3}{|c|}{ Binder phase } & \multicolumn{3}{c|}{ Ceramic phase } \\
\cline { 2 - 8 } & $\begin{array}{c}\text { Observed } \\
\text { by XRD }\end{array}$ & $\mathbf{H}(\mathbf{G P a})$ & $\mathbf{E}(\mathbf{G P a})$ & $\begin{array}{c}\text { Observed by } \\
\text { XRD }\end{array}$ & $\mathbf{H}(\mathbf{G P a})$ & $\mathbf{E}(\mathbf{G P a})$ \\
\hline 20Co0G & $\mathrm{Ti}_{\mathrm{x}} \mathrm{Ta}_{1-\mathrm{x}} \mathrm{Co}_{2}$ & $17.2 \pm 1.3$ & $317 \pm 7$ & $\mathrm{Ti}_{0.95} \mathrm{Ta}_{0.05} \mathrm{C}_{0.5} \mathrm{~N}_{0.5}$ & $36.0 \pm 2.2$ & $530 \pm 15$ \\
\hline 20Co1.8G & $\mathrm{Ti}_{\mathrm{x}} \mathrm{Ta}_{1-\mathrm{x}} \mathrm{Co}_{3}$ & $10.2 \pm 1.7$ & $280 \pm 4$ & $\mathrm{Ti}_{0.95} \mathrm{Ta}_{0.05} \mathrm{C}_{0.5} \mathrm{~N}_{0.5}$ & $36.8 \pm 3.2$ & $533 \pm 16$ \\
\hline 30Co2.2G & $\alpha-C o$ & $8.6 \pm 1.8$ & $264 \pm 12$ & $\mathrm{Ti}_{0.95} \mathrm{Ta}_{0.05} \mathrm{C}_{0.5} \mathrm{~N}_{0.5}$ & $35.7 \pm 3.5$ & $521 \pm 24$ \\
\hline
\end{tabular}




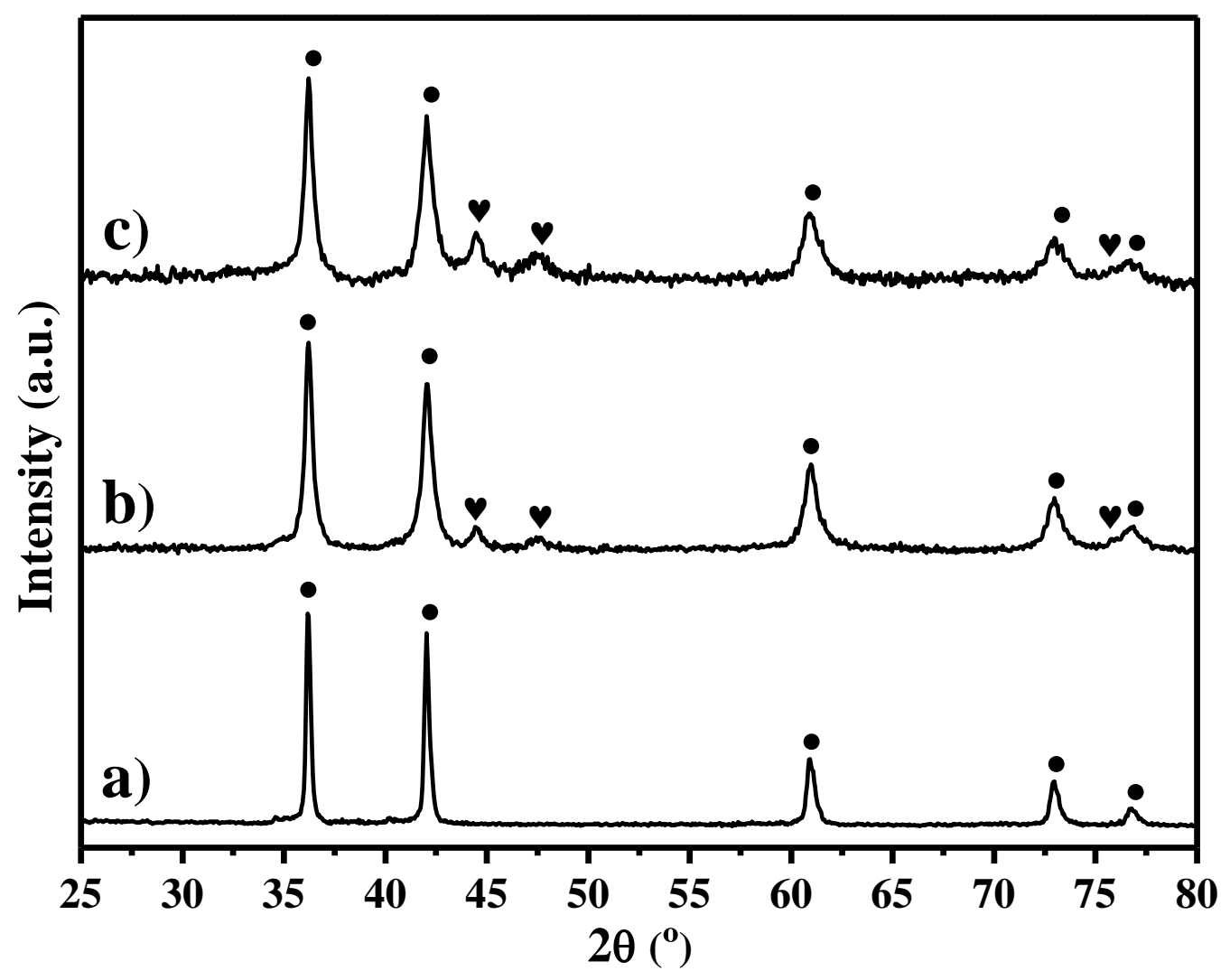

Figure 1. 

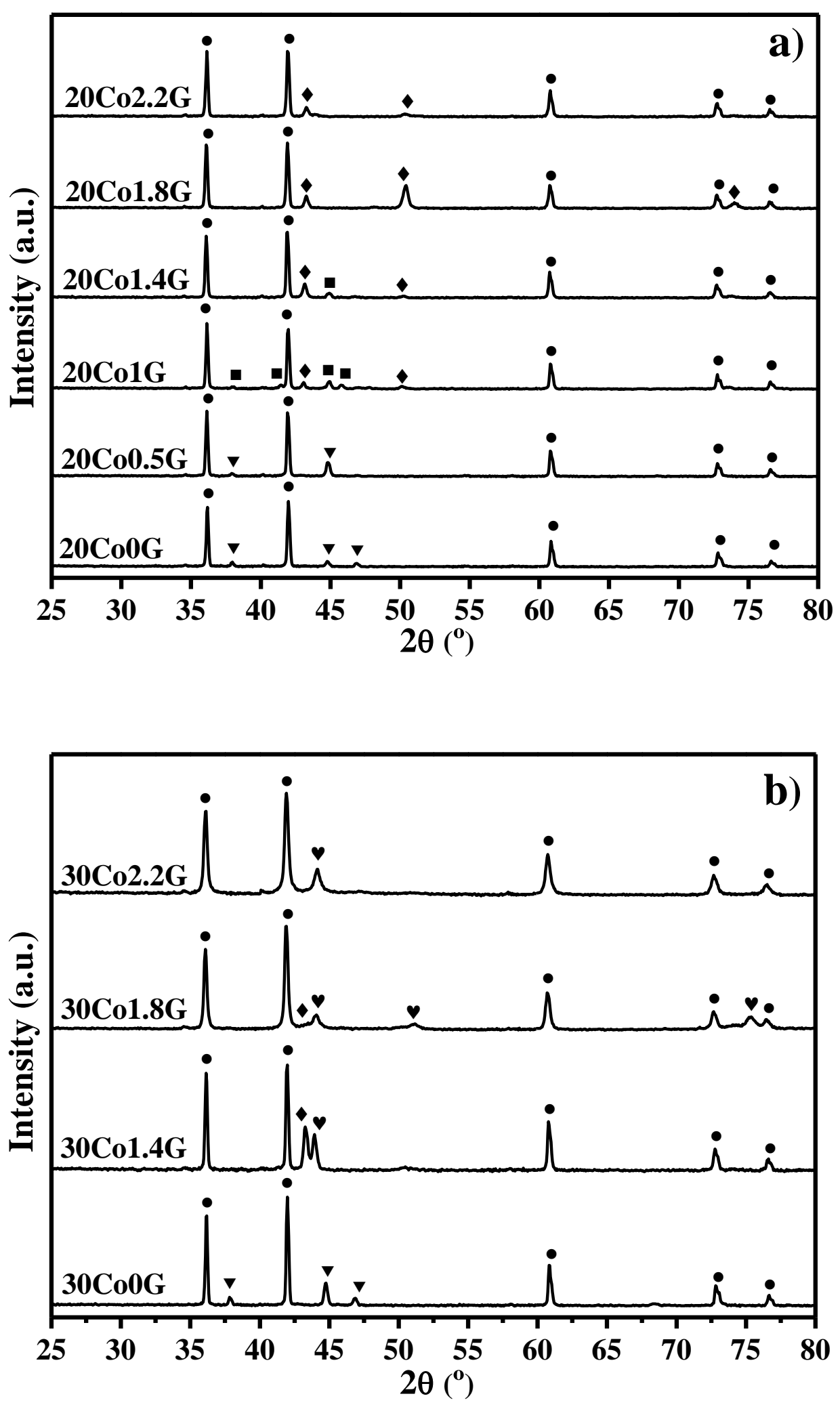

Figure 2 


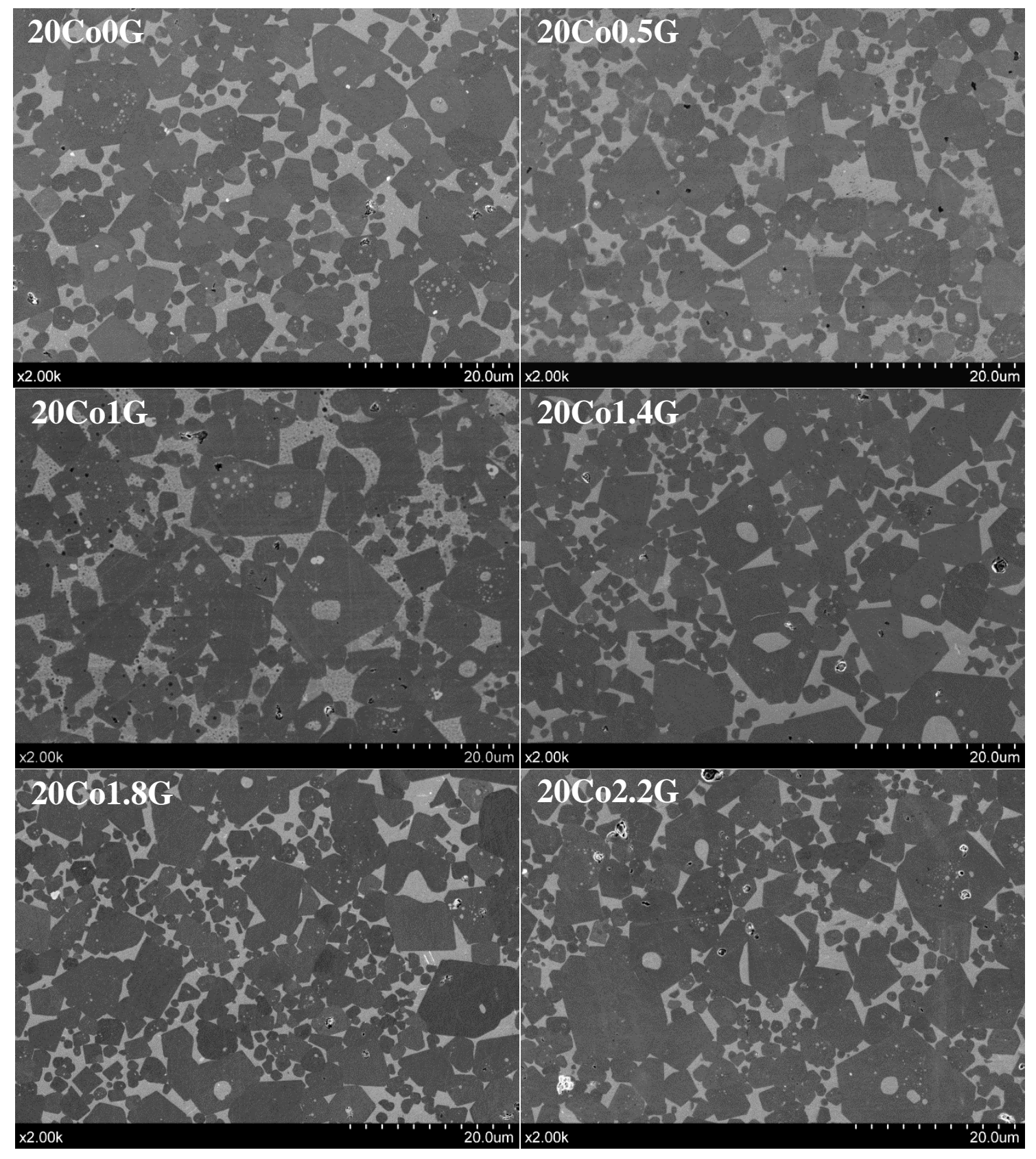

Figure 3. 


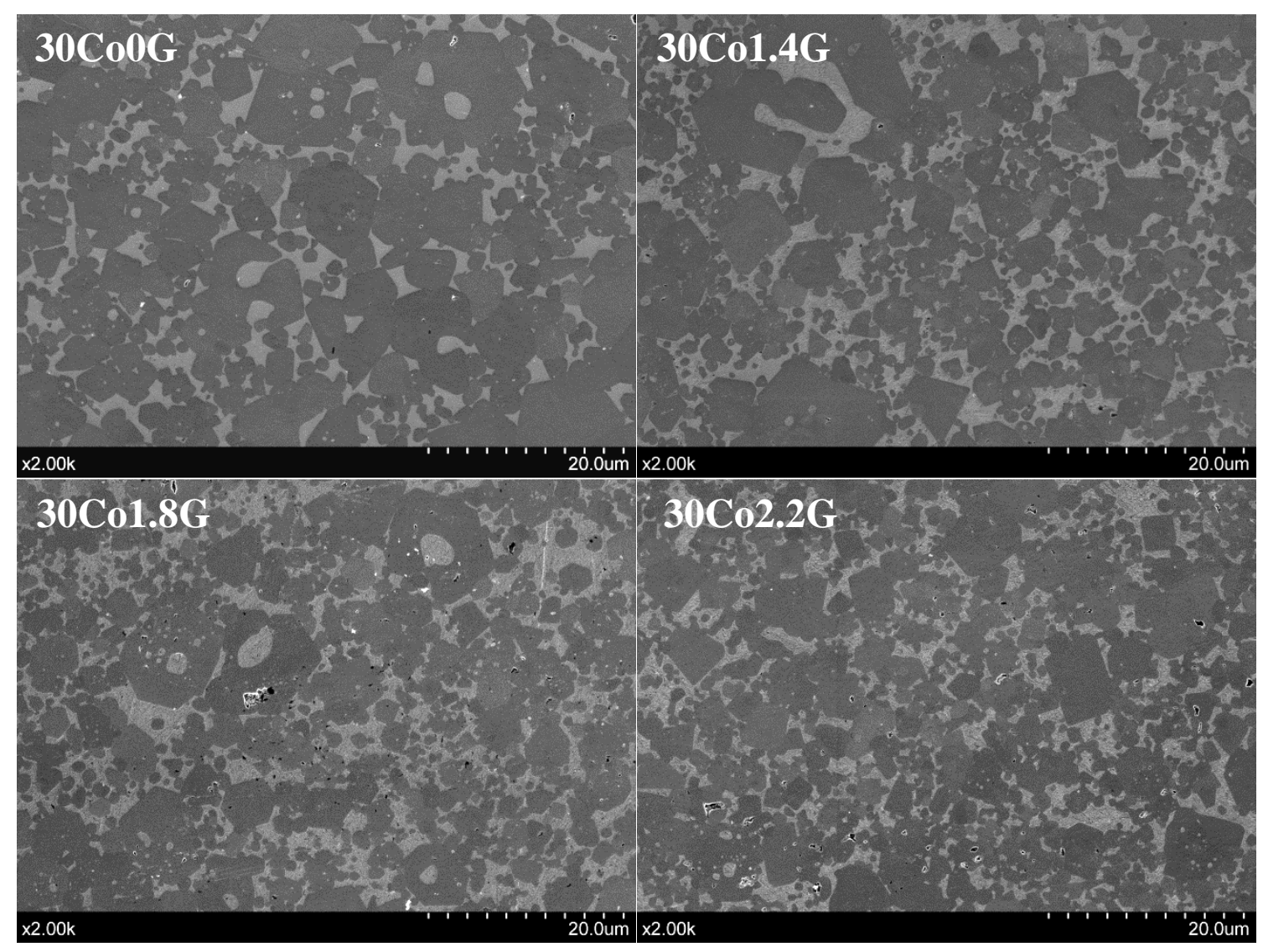

Figure 4. 


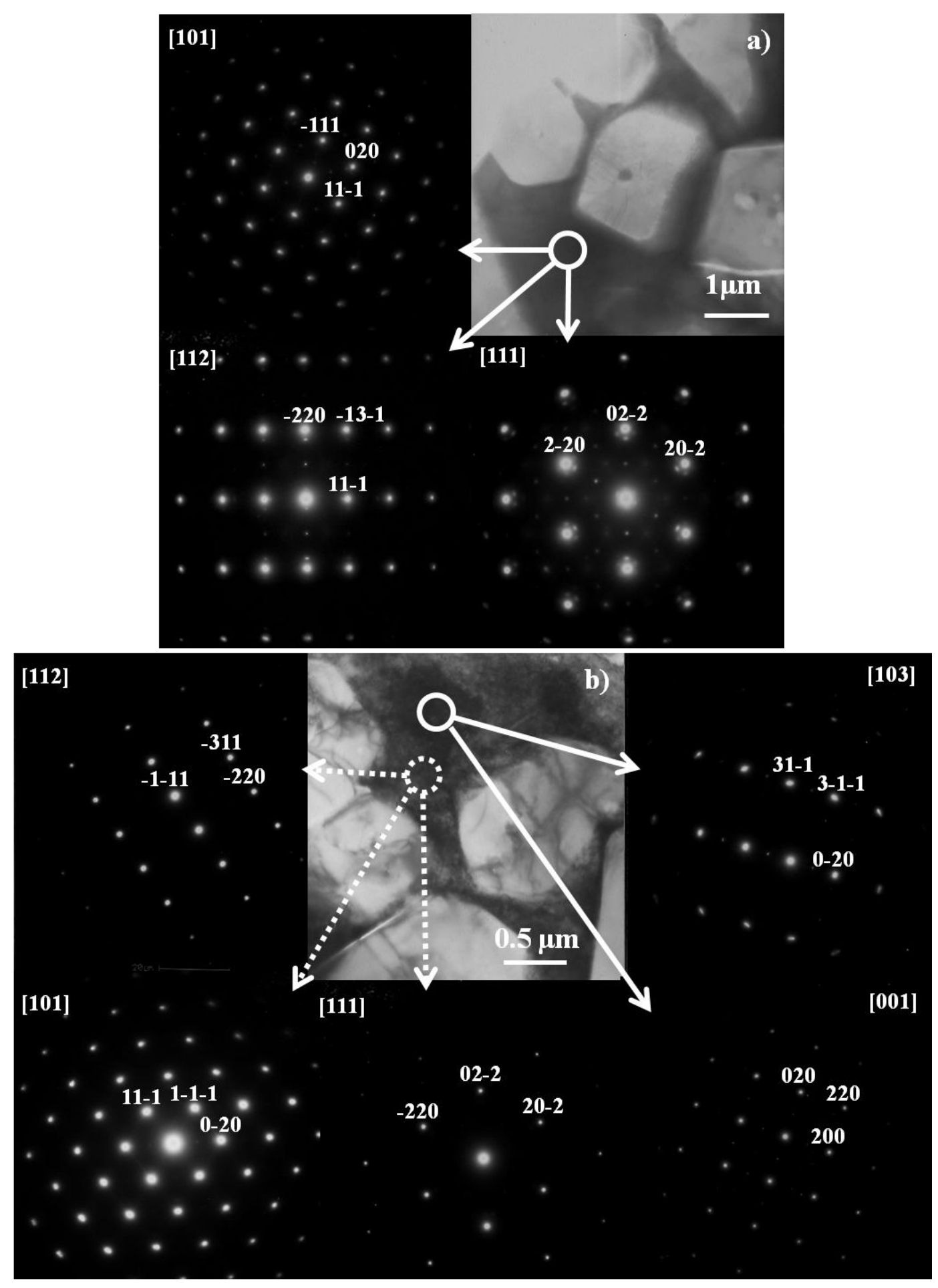

Figure 5. 

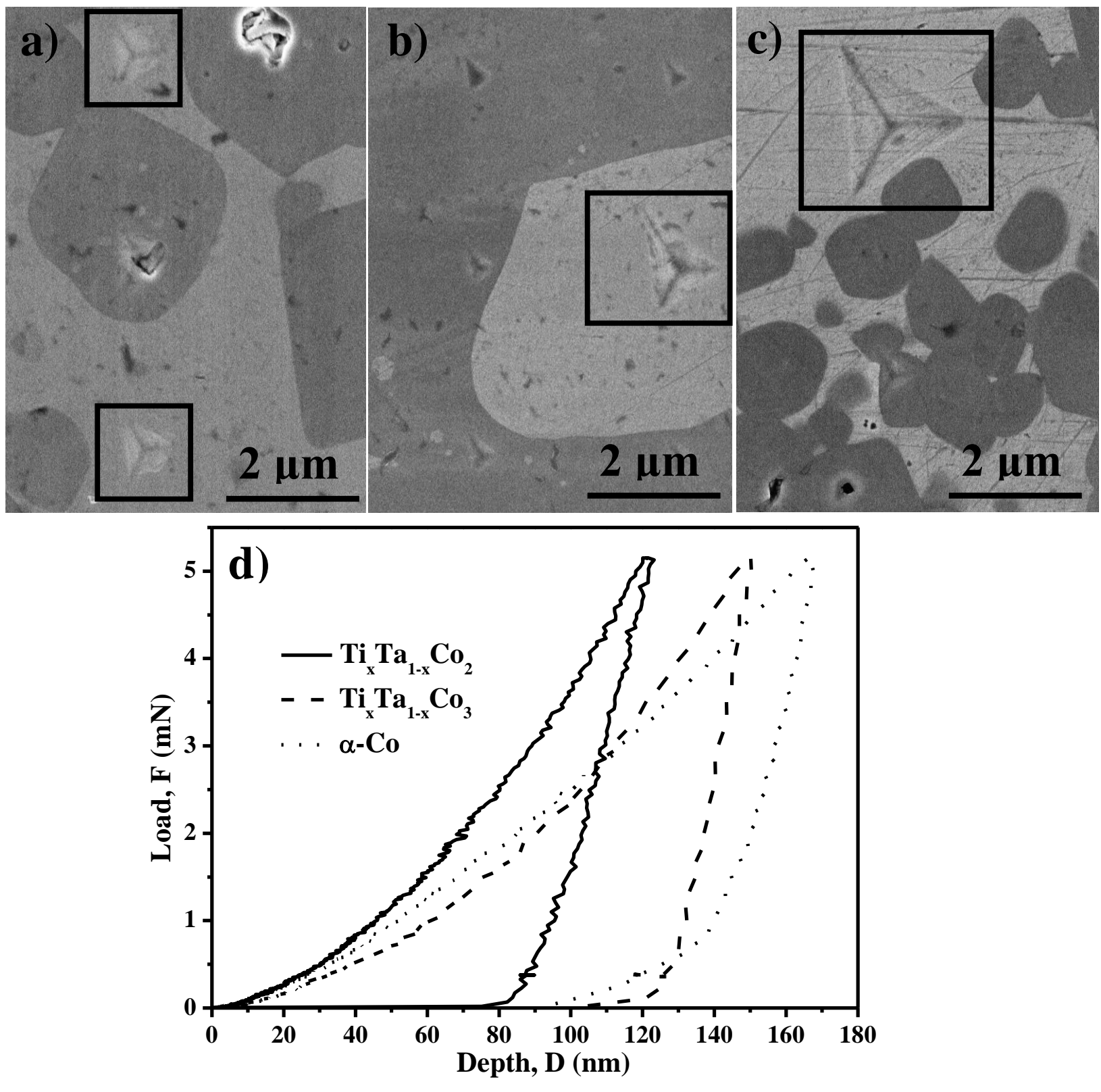

Figure 6. 


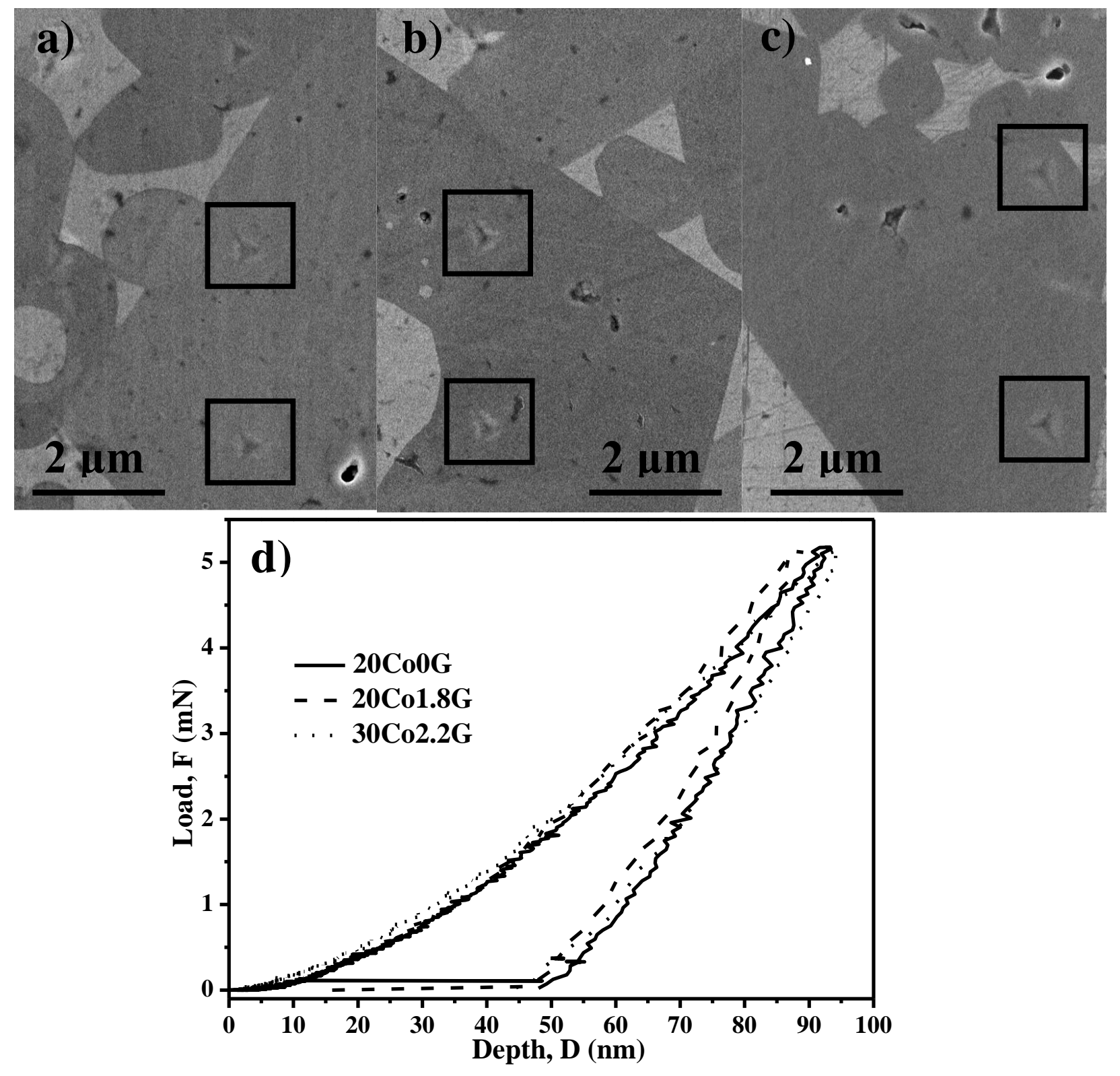

Figure 7. 